\title{
Características de carcaça de cordeiros Hampshire Down e Santa Inês sob diferentes fotoperíodos
}

\author{
José Luiz de Sá(1), Edson Ramos de Siqueira(2), Cristiane Otto de Sá(1), Roberto de Oliveira Roça ${ }^{(3)}$ \\ e Simone Fernandes ${ }^{(2)}$
}

\begin{abstract}
(1)Embrapa Semi-Árido, BR 428, Km 152, Caixa Postal 23, CEP 56302-970 Petrolina, PE. E-mail: sa@cpatc.embrapa.br, cris@cpatc.embrapa.br (2)Universidade Estadual Paulista (Unesp), Fac. de Medicina Veterinária e Zootecnia, Dist. Rubião Júnior, s/no, CEP 18618-000 Botucatu, SP. E-mail: ersiqueira@fca.unesp.br (3)Unesp, Fac. de Ciências Agrárias, Fazenda Experimental Lageado, s/no, Caixa Postal 237, CEP 18603-970 Botucatu, SP. E-mail: robertoroca@fca.unesp.br
\end{abstract}

Resumo - O objetivo deste trabalho foi avaliar o efeito do fotoperíodo e da raça nas características de carcaça de cordeiros machos Hampshire Down e Santa Inês. Sete cordeiros Hampshire Down e sete Santa Inês foram submetidos a fotoperíodo de 12 horas luz x 12 horas escuro (curto) e de 18 horas luz x 6 horas escuro (longo). Após o desmame, os cordeiros foram alojados em baias individuais de acordo com os tratamentos. Ao atingirem $31 \mathrm{~kg}$ de peso vivo, foram abatidos e a carcaça e os componentes não-constituintes da carcaça foram pesados. Cordeiros Santa Inês apresentaram peso de carcaça quente superior ao dos Hampshire e maior rendimento comercial. Cordeiros Santa Inês apresentaram maior peso de sangue, coração, pulmão, rins e baço. Já os cordeiros Hampshire Down apresentaram pesos de pele, patas e aparelho gastrintestinal cheio superiores aos do Santa Inês. Os cordeiros Santa Inês apresentaram maior largura de garupa e comprimento de perna do que os Hampshire Down. Os cordeiros Santa Inês apresentaram porcentagem de costela descoberta e baixos maior do que os Hampshire Down, com maior porcentagem de perna. A raça influencia mais as características de carcaça do que o fotoperíodo.

Termos para indexação: ovino, luminosidade, raça, rendimento.

\section{Carcass characteristics of Hampshire Down and Santa Inês ram lambs under different photoperiods}

\begin{abstract}
The objective of this work was to evaluate the effect of photoperiod and breed on carcass characteristics. Seven Hampshire Down and seven Santa Inês ram lambs were assigned to two photoperiods: 12 hours light x 12 hours dark, or short photoperiod, and to 18 hours of light x 6 hours of dark, or long photoperiod. After weaning, the lambs were housed in individual stalls. The lambs were weighed weekly until slaughter weight of $31 \mathrm{~kg}$. After slaughter, the carcass and the non-carcass components were weighed. Santa Inês lambs had higher hot carcass weight than Hampshire Down and also a higher commercial dressing percentage. Santa Inês lambs had higher blood, heart, lung, kidneys and spleen weight. The Hampshire Down lambs had higher skin, feet, full stomach and full intestine weight. Santa Inês lambs had higher width hindquarters and leg length than the Hampshire Down. Santa Inês lambs had higher percentage of discovered rib and low and the Hampshire Down lambs, higher percentage of leg. Breed influences more the carcass characteristics than photoperiod.
\end{abstract}

Index terms: sheep, light, breed, commercial dressing.

\section{Introdução}

A produção de carne ovina depende principalmente das pastagens, que são consideradas como um ingrediente de baixo custo na alimentação do rebanho. Entretanto, o uso exclusivo de pasto é limitado em razão da flutuação na disponibilidade e valor nutritivo das forrageiras ao longo do ano, resultando em baixa produtividade animal (Moron Fuenmayor \& Clavero, 1999).
O sistema intensivo é caracterizado pelo confinamento dos cordeiros no período de terminação e por uma dieta com alta proporção de concentrados (McClure et al., 1994; McClure et al., 1995). Apesar da prática do confinamento elevar os custos e aumentar a mão-deobra, em algumas situações é extremamente vantajosa (Notter et al., 1991; Dimsoski et al., 1999). Em determinados estados do Brasil, entre os quais São Paulo e Paraná, o confinamento de cordeiros tem sido adotado 
com freqüência. Estas regiões comportam áreas pequenas para a criação dos animais, os rebanhos são relativamente pequenos, a lotação é elevada e a terra é valorizada. Nessas condições, a produtividade por hectare deve ser alta, para que a atividade seja economicamente viável. Os cordeiros devem apresentar elevadas taxas de crescimento e atingir precocemente o peso de abate. Nesse caso, a terminação de cordeiros em confinamento é recomendada (Otto et al., 1997).

A utilização do confinamento permite o emprego de novas tecnologias, que podem contribuir para aumentar a produção de carne e melhorar a qualidade da carcaça. $\mathrm{O}$ aumento da luminosidade a que o animal é exposto pode, em determinadas situações, elevar o ganho de peso (Eisemann et al., 1984), a produção de leite (Kann, 1997) e o crescimento da lã (Butler, 1994). Em revisão realizada por Forbes (1982), são citados vários trabalhos nos quais o aumento da luminosidade estimulou o consumo alimentar e o ganho de peso, como também observado por Brinklow \& Forbes (1984).

O produtor de carne ovina tem como objetivo a produção em quantidade, pois é geralmente remunerado por quilo de cordeiro. Entretanto, esta forma de comercialização pode colocar no mercado carcaças de baixa qualidade, o que diminuiria a aceitação do produto pelo consumidor. Portanto, alterações que ocorrem na carcaça, em razão de um manejo ou de uma nova tecnologia, devem ser consideradas.

O objetivo deste trabalho foi avaliar o efeito de dois fotoperíodos - longo e curto - e de duas raças - Santa Inês e Hampshire Down - sobre as características da carcaça e dos componentes não-constituintes da carcaça de cordeiros machos terminados em confinamento e abatidos com o mesmo peso vivo.

\section{Material e Métodos}

O experimento foi realizado no Setor de Ovinocultura da Fac. de Medicina Veterinária e Zootecnia e no Laboratório de Tecnologia dos Produtos de Origem Animal, da Fac. de Ciências Agronômicas, ambos pertencentes à Unesp, campus de Botucatu.

Foram utilizados 28 cordeiros machos e inteiros, sendo 14 da raça Hampshire Down e 14 da raça Santa Inês, terminados em confinamento. Os animais foram divididos em dois fotoperíodos. Sete cordeiros Hampshire Down e sete Santa Inês foram submetidos ao fotoperíodo de 12 horas de luz x 12 horas de escuro, considerado curto neste experimento. As luzes eram acesas às 6 horas e apagadas às 18 horas. Este é um fotoperíodo semelhante ao que ocorre naturalmente, na época de terminação de cordeiros.

Os outros sete animais Hampshire Down e sete Santa Inês foram expostos ao fotoperíodo longo de 18 horas de luz x 6 horas de escuro. Neste fotoperíodo, as luzes eram acesas às 6 horas e apagadas às 24 horas. A luz artificial foi utilizada em ambos os fotoperíodos e a intensidade na altura dos olhos dos cordeiros era de 350 lux. A distribuição dos animais nos tratamentos foi ao acaso, de acordo com um arranjo fatorial $2 \times 2$, de duas raças e dois fotoperíodos.

Com idade de aproximadamente 60 dias e peso médio de $15 \mathrm{~kg}$ para os Santa Inês e $19 \mathrm{~kg}$ para os Hampshire Down, os cordeiros foram desmamados, vermifugados e distribuídos nos tratamentos. Durante a fase de terminação permaneceram em baias individuais, recebendo à vontade dieta balanceada com $16 \%$ de proteína bruta $(\mathrm{PB})$ e $75 \%$ de nutrientes digestíveis totais (NDT), calculada para um ganho médio diário de $250 \mathrm{~g}$, segundo recomendações do NRC (1985).

As pesagens dos animais foram realizadas semanalmente durante o experimento, no mesmo horário, à tarde, em balança mecânica. Os cordeiros foram abatidos com aproximadamente $31 \mathrm{~kg}$ de peso vivo, com idade média de 135 dias para o Santa Inês e 110 dias para o Hampshire Down. No dia anterior ao do abate, uma última pesagem era realizada para constatar o peso de referência. Após esta pesagem, iniciava-se o jejum préabate de 18 horas, durante o qual só havia fornecimento de água.

No dia do abate, os cordeiros foram pesados imediatamente antes da degola, para obtenção do peso vivo ao abate. A determinação do peso vivo vazio se fez pela diferença entre o peso vivo ao abate e o peso do conteúdo gastrintestinal. Já o peso da carcaça quente foi registrado logo após a evisceração e retirada dos elementos não pertencentes à carcaça. $\mathrm{O}$ peso da carcaça fria foi obtido após 24 horas de resfriamento a $4{ }^{\circ} \mathrm{C}$. O rendimento verdadeiro foi calculado por meio da relação entre o peso da carcaça quente e o peso vivo vazio, e o rendimento comercial, pela relação entre o peso da carcaça fria e o peso vivo ao abate. A perda no resfriamento foi calculada por meio da relação entre o peso de carcaça fria e o peso da carcaça quente. Os componentes não-constituintes da carcaça - sangue, cauda, testículos, pele, cabeça, patas, coração, pulmão, traquéia, aparelho gastrintestinal vazio, estômago, intestino, aparelho urinário, pênis, fígado, rins e baço - foram também pesados no dia do abate. 
Para mensuração do $\mathrm{pH}$ foi aberto pequeno orifício no músculo Longissimus dorsi para introduzir o eletrodo de penetração específico para carcaças. $\mathrm{O} \mathrm{pH}$ foi medido imediatamente após o abate $\left(\mathrm{pH}_{0}\right), 45$ minutos $\left(\mathrm{pH}_{45}\right)$ e 24 horas $\left(\mathrm{pH}_{24}\right)$ depois.

Medidas da carcaça, tais como comprimento externo - medida que inicia na cruz da espádua e termina no início das vértebras coccígeas -, comprimento interno - distância máxima entre o bordo anterior da sínfise ísquio-pubiana e o bordo anterior da primeira costela-, largura de garupa - largura máxima entre os trocânteres de ambos os fêmures -, comprimento da perna - distância entre o períneo e o bordo anterior da superfície tarso-metatarsiana - e perímetro da garupa - medida da superfície externa da garupa -, foram avaliadas na carcaça resfriada.

Quanto ao índice de compacidade da carcaça, utilizou-se a relação entre o peso da carcaça fria e o comprimento interno da carcaça e quanto ao índice de compacidade da perna, relacionou-se a largura da garupa com o comprimento da perna.

O grau de gordura de cobertura foi determinado mediante apreciação visual da carcaça, utilizando-se uma escala de 5 pontos, sendo atribuído valor 1 para excessivamente magra e 5 para excessivamente gorda. O grau de conformação consistiu na avaliação visual da carcaça como um todo, mas levando-se em consideração as diferentes regiões anatômicas e a espessura de seus planos musculares e adiposos, em relação ao tamanho do esqueleto que a suporta, sendo 1 atribuído à conformação muito pobre e 5 à excelente.

A carcaça foi dividida ao meio e a metade esquerda subdividida em sete regiões anatômicas (ColomerRocher \& Espejo, 1972), as quais foram pesadas e descritas. A paleta compreende a região que tem como base anatômica a espádua, o úmero, o cúbito, o rádio e o carpo; o pescoço refere-se à região anatômica das sete vértebras cervicais e foi obtido por um corte oblíquo

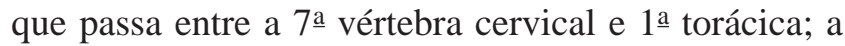
costela descoberta possui como base óssea as cinco primeiras vértebras torácicas, junto com a metade superior do corpo das costelas correspondentes; a costela compreende as oito últimas vértebras torácicas, associadas à metade superior das costelas correspondentes; $\mathrm{o}$ lombo, com base anatômica nas vértebras lombares, é a zona que incide perpendicularmente com a coluna, entre a $13^{\underline{a}}$ vértebra torácica -1 a lombar e última lombar1 sacra; os baixos são obtidos por meio do traçado de uma linha reta desde o bordo dorsal do reto do abdômen à ponta do externo; a perna é o conjunto que compreende as regiões glútea, femural e da perna, tendo como base óssea o tarso, tíbia, fêmur, ísquio, púbis e íleo. Separa-se por corte perpendicular à coluna, entre as duas últimas vértebras lombares.

As variáveis foram submetidas à análise de variância para delineamento inteiramente casualizado, em esquema fatorial de dois fotoperíodos $\mathrm{x}$ duas raças pelo procedimento General Linear Model (GLM) do programa SAS (1989). As médias foram contrastadas pelo teste de Tukey a 5\% de probabilidade.

\section{Resultados e Discussão}

O fotoperíodo e a raça não afetaram o ganho de peso dos animais (Tabela 1). Uma vez fixado o peso de $31 \mathrm{~kg}$ para o abate dos cordeiros, não foram observadas diferenças significativas $(\mathrm{P}>0,05)$ para peso vivo ao abate nem para peso vivo vazio entre raças e fotoperíodos, apesar dos cordeiros Hampshire Down terem sido abatidos com uma idade menor, 110 dias, do que os cordeiros Santa Inês, 135 dias, em razão do maior peso inicial. $\mathrm{O}$ peso da carcaça quente foi superior nos cordeiros Santa Inês, porém, após a perda ocorrida no resfriamento, não foram observadas diferenças quanto ao peso de carcaça fria. $\mathrm{O}$ rendimento verdadeiro não foi afetado pelos fatores principais, mas cordeiros submetidos ao fotoperíodo curto e cordeiros Santa Inês apresentaram maior rendimento comercial. Não foi observada interação raça $\mathrm{x}$ fotoperíodo em nenhuma das variáveis estudadas (Tabela 2).

Em experimentos nos quais os cordeiros foram abatidos por idade ou após um determinado tempo de exposição a diferentes fotoperíodos, observou-se que o

Tabela 1. Ganho de peso diário e consumo diário de matéria seca, do início do experimento até o peso de abate de $31 \mathrm{~kg}$, de cordeiros Santa Inês e Hampshire Down, sob dois fotoperíodos ${ }^{(1)}$.

\begin{tabular}{lcccc}
\hline Variável & \multicolumn{2}{c}{ Fotoperíodo } & \multirow{2}{*}{ Média CV (\%) } \\
\cline { 2 - 3 } & Curto & Longo & & \\
\hline Ganho médio diário $(\mathrm{kg})$ & & & & \\
$\quad$ Santa Inês & $0,209 \pm 0,040$ & $0,216 \pm 0,009$ & 0,213 & \\
Hampshire Down & $0,247 \pm 0,068$ & $0,256 \pm 0,059$ & 0,251 & \\
\hline Média & 0,228 & 0,236 & & 11,39 \\
\hline Consumo médio diário (kg) & & & & \\
$\quad$ Santa Inês & $1,058 \pm 0,061$ & $1,113 \pm 0,041$ & $1,085 \mathrm{~A}$ & \\
$\quad$ Hampshire Down & $0,988 \pm 0,069$ & $0,993 \pm 0,050$ & $0,990 \mathrm{~B}$ & \\
\hline Média & 1,023 & 1,053 & & \\
\hline
\end{tabular}

${ }^{(1)}$ Médias \pm desvio-padrão seguidas de letras diferentes diferem entre si a $5 \%$ de probabilidade pelo teste de Tukey. 
fotoperíodo longo propiciou um peso de carcaça superior, decorrente do maior ganho de peso dos animais expostos a essa condição (Forbes, 1982). Neste trabalho, os cordeiros foram abatidos com um peso fixo e o ganho de peso não sofreu interferência da luminosidade e da raça, e por isso as variações no peso das carcaças não foram grandes. O peso de carcaça quente dos cordeiros Santa Inês foi superior ao dos Hampshire Down. Este maior peso de carcaça do Santa Inês era esperado, já que essa raça possui uma pele mais leve do que a do Hampshire Down. Além disso, os cordeiros Hampshire Down revelaram maior conteúdo no aparelho gastrintestinal do que os Santa Inês após as mesmas 18 horas de jejum (Tabela 3 ). Uma vez que o rendimento de carcaça está relacionado com o tempo de jejum, o conteúdo do aparelho gastrintestinal e o peso das extremidades e dos órgãos, os animais Santa Inês apresentaram um rendimento comercial de carcaça superior ao

Tabela 2. Peso vivo e de carcaça, perda no resfriamento e rendimentos verdadeiro e comercial de cordeiros Santa Inês e Hampshire Down, sob dois fotoperíodos ${ }^{(1)}$.

\begin{tabular}{|c|c|c|c|c|}
\hline \multirow[t]{2}{*}{ Variável } & \multicolumn{2}{|c|}{ Fotoperíodo } & \multirow[t]{2}{*}{ Média } & \multirow[t]{2}{*}{$\mathrm{CV}(\%)$} \\
\hline & Curto & Longo & & \\
\hline $\begin{array}{l}\text { Peso vivo ao abate }(\mathrm{kg}) \\
\text { Santa Inês } \\
\text { Hampshire Down }\end{array}$ & $\begin{array}{l}29,79 \pm 0,95 \\
29,57 \pm 1,48\end{array}$ & $\begin{array}{l}29,36 \pm 0,75 \\
30,36 \pm 0,85\end{array}$ & $\begin{array}{l}29,57 \\
29,96 \\
\end{array}$ & 3,52 \\
\hline Média & 29,68 & 29,86 & & \\
\hline $\begin{array}{l}\text { Peso vivo vazio }(\mathrm{kg}) \\
\text { Santa Inês } \\
\text { Hampshire Down } \\
\end{array}$ & $\begin{array}{l}26,13 \pm 1,18 \\
24,63 \pm 1,48\end{array}$ & $\begin{array}{l}25,44 \pm 0,83 \\
25,17 \pm 1,23\end{array}$ & $\begin{array}{l}25,79 \\
24,90 \\
\end{array}$ & 4,75 \\
\hline Média & 25,38 & 25,31 & & \\
\hline $\begin{array}{l}\text { Peso carcaça quente }(\mathrm{kg}) \\
\text { Santa Inês } \\
\text { Hampshire Down }\end{array}$ & $\begin{array}{l}14,24 \pm 0,69 \\
13,23 \pm 0,10\end{array}$ & $\begin{array}{l}13,63 \pm 0,40 \\
13,16 \pm 0,53\end{array}$ & $\begin{array}{l}13,94 \mathrm{~A} \\
13,19 \mathrm{~B}\end{array}$ & 5,36 \\
\hline Média & 13,74 & 13,39 & & \\
\hline $\begin{array}{l}\text { Peso carcaça fria }(\mathrm{kg}) \\
\text { Santa Inês } \\
\text { Hampshire Down }\end{array}$ & $\begin{array}{l}13,66 \pm 0,80 \\
12,94 \pm 1,05\end{array}$ & $\begin{array}{l}12,86 \pm 0,41 \\
12,84 \pm 0,47\end{array}$ & $\begin{array}{l}13,26 \\
12,89\end{array}$ & 5,59 \\
\hline Média & 13,30 & 12,85 & & \\
\hline $\begin{array}{l}\text { Peda no resfriamento }(\mathrm{kg}) \\
\text { Santa Inês } \\
\text { Hampshire Down }\end{array}$ & $\begin{array}{l}4,13 \pm 2,36 \\
2,14 \pm 0,93\end{array}$ & $\begin{array}{l}5,56 \pm 3,33 \\
2,43 \pm 0,74\end{array}$ & $\begin{array}{l}4,85 \mathrm{~A} \\
2,88 \mathrm{~B}\end{array}$ & 59,52 \\
\hline Média & 3,40 & 3,14 & & \\
\hline $\begin{array}{l}\text { Rendimento verdadeiro }(\mathrm{kg}) \\
\text { Santa Inês } \\
\text { Hampshire Down }\end{array}$ & $\begin{array}{l}54,51 \pm 1,28 \\
53,66 \pm 1,65\end{array}$ & $\begin{array}{l}53,62 \pm 2,40 \\
52,32 \pm 1,83\end{array}$ & $\begin{array}{l}54,07 \\
52,99\end{array}$ & 3,43 \\
\hline Média & 54,09 & 52,97 & & \\
\hline $\begin{array}{l}\text { Rendimento comercial (kg) } \\
\text { Santa Inês } \\
\text { Hampshire Down }\end{array}$ & $\begin{array}{l}45,85 \pm 2,33 \\
43,74 \pm 2,09\end{array}$ & $\begin{array}{l}43,64 \pm 2,01 \\
42,42 \pm 1,34\end{array}$ & $\begin{array}{l}44,75 \mathrm{~A} \\
43,08 \mathrm{~B}\end{array}$ & 4,51 \\
\hline Média & $44,79 a$ & $43,03 b$ & & \\
\hline
\end{tabular}

Tabela 3. Peso $(\mathrm{kg})$ dos componentes não-constituintes da carcaça de cordeiros Santa Inês e Hampshire Down, sob dois fotoperíodos $^{(1)}$.

\begin{tabular}{|c|c|c|c|c|}
\hline \multirow[t]{2}{*}{ Componente } & \multicolumn{2}{|c|}{ Fotoperíodo } & \multirow[t]{2}{*}{ Média } & \multirow{2}{*}{$\begin{array}{l}\mathrm{CV} \\
(\%)\end{array}$} \\
\hline & Curto & Longo & & \\
\hline Sangue & & & & 8,04 \\
\hline Santa Inês & $1,43 \pm 0,11$ & $1,34 \pm 0,11$ & $1,39 \mathrm{~A}$ & \\
\hline Hampshire Down & $1,23 \pm 0,10$ & $1,27 \pm 0,11$ & $1,25 \mathrm{~B}$ & \\
\hline Média & 1,33 & 1,31 & & \\
\hline Cauda & & & & 27,42 \\
\hline Santa Inês & $0,105 \pm 0,03$ & $0,10 \pm 0,023$ & $0,103 \mathrm{~A}$ & \\
\hline Hampshire Down & 0 & 0 & 0B & \\
\hline Média & 0,053 & 0,050 & & \\
\hline Testículos & & & & 16,57 \\
\hline Santa Inês & $0,309 \pm 0,046$ & $0,290 \pm 0,057$ & 0,299 & \\
\hline Hampshire Down & $0,302 \pm 0,045$ & $0,260 \pm 0,043$ & 0,281 & \\
\hline Média & 0,305 & 0,275 & & \\
\hline Pele & & & & 11,85 \\
\hline Santa Inês & $1,83 \pm 0,23$ & $1,79 \pm 0,18$ & $1,81 \mathrm{~B}$ & \\
\hline Hampshire Down & $2,33 \pm 0,23$ & $2,29 \pm 0,32$ & $2,31 \mathrm{~A}$ & \\
\hline Média & 2,08 & 2,04 & & \\
\hline Cabeça & & & & 7,59 \\
\hline Santa Inês & $1,87 \pm 0,09$ & $1,73 \pm 0,05$ & 1,80 & \\
\hline Hampshire Down & $1,65 \pm 0,23$ & $1,75 \pm 0,07$ & 1,70 & \\
\hline Média & 1,76 & 1,74 & & \\
\hline Patas & & & & 5,80 \\
\hline Santa Inês & $0,763 \pm 0,038$ & $0,737 \pm 0,035$ & $0,750 \mathrm{~B}$ & \\
\hline Hampshire Down & $0,771 \pm 0,049$ & $0,801 \pm 0,054$ & $0,786 \mathrm{~A}$ & \\
\hline Média & 0,767 & 0,769 & & \\
\hline Coração & & & & 14,72 \\
\hline Santa Inês & $0,214 \pm 0,032$ & $0,206 \pm 0,028$ & $0,230 \mathrm{~A}$ & \\
\hline Hampshire Down & $0,168 \pm 0,033$ & $0,192 \pm 0,020$ & $0,180 \mathrm{~B}$ & \\
\hline Média & 0,191 & 0,199 & & \\
\hline Pulmão/traquéia & & & & 12,24 \\
\hline Santa Inês & $0,898 \pm 0,105$ & $0,831 \pm 0,090$ & $0,865 \mathrm{~A}$ & \\
\hline Hampshire Down & $0,784 \pm 0,095$ & $0,753 \pm 0,109$ & $0,769 \mathrm{~B}$ & \\
\hline Média & 0,841 & 0,792 & & \\
\hline Aparelho gastrointesti & nal cheio & & & 11,51 \\
\hline Santa Inês & $6,17 \pm 0,49$ & $6,40 \pm 0,34$ & $6,28 \mathrm{~B}$ & \\
\hline Hampshire Down & $7,31 \pm 0,97$ & $7,61 \pm 1,10$ & $7,46 \mathrm{~A}$ & \\
\hline Média & 6,74 & 7,00 & & \\
\hline Estômago & & & & 18,79 \\
\hline Santa Inês & $1,24 \pm 0,14$ & $1,26 \pm 0,24$ & 1,25 & \\
\hline Hampshire Down & $1,11 \pm 0,30$ & $1,05 \pm 0,16$ & 1,08 & \\
\hline Média & 1,18 & 1,15 & & \\
\hline Intestino & & & & 11,29 \\
\hline Santa Inês & $1,27 \pm 0,12$ & $1,23 \pm 0,15$ & 1,25 & \\
\hline Hampshire Down & $1,26 \pm 0,17$ & $1,37 \pm 0,15$ & 1,32 & \\
\hline Média & 1,27 & 1,30 & & \\
\hline Aparelho urinário e $\mathrm{p}$ & nis & & & 20,39 \\
\hline Santa Inês & $0,186 \pm 0,030$ & $0,200 \pm 0,035$ & 0,193 & \\
\hline Hampshire Down & $0,192 \pm 0,043$ & $0,183 \pm 0,045$ & 0,188 & \\
\hline Média & 0,189 & 0,191 & & \\
\hline Fígado & & & & 9,94 \\
\hline Santa Inês & $0,578 \pm 0,056$ & $0,561 \pm 0,051$ & 0,570 & \\
\hline Hampshire Down & $0,527 \pm 0,051$ & $0,566 \pm 0,063$ & 0,547 & \\
\hline Média & 0,553 & 0,564 & & \\
\hline Rins & & & & 18,62 \\
\hline Santa Inês & $0,253 \pm 0,049$ & $0,220 \pm 0,034$ & $0,236 \mathrm{~A}$ & \\
\hline Hampshire Down & $0,170 \pm 0,037$ & $0,150 \pm 0,024$ & $0,160 \mathrm{~B}$ & \\
\hline Média & 0,211 & 0,185 & & \\
\hline Baço & & & & 19,68 \\
\hline Santa Inês & $0,081 \pm 0,015$ & $0,069 \pm 0,009$ & $0,075 \mathrm{~A}$ & \\
\hline Hampshire Down & $0,044 \pm 0,007$ & $0,054 \pm 0,015$ & $0,049 \mathrm{~B}$ & \\
\hline Média & 0,062 & 0,061 & & \\
\hline
\end{tabular}

${ }^{(1)}$ Médias \pm desvio-padrão seguidas de letras diferentes diferem entre si a $5 \%$ de probabilidade pelo teste de Tukey. 
dos Hampshire Down. O peso de carcaça fria não diferiu entre as raças, o que indica que os cordeiros Santa Inês tiveram maior perda no resfriamento, provavelmente, pela maior quantidade de gordura de cobertura na carcaça. A perda foi de 4,85\% para o Santa Inês e 2,29\% para o Hampshire Down.

Vários fatores afetam o peso e o rendimento de carcaça, entre eles alimentação, sexo, sistema de produção, peso ao abate, idade e raça (Lee et al., 1990; Osorio et al., 1996; Hopkins \& Fogarty, 1998; Hopkins et al., 1998; Dimsoski et al., 1999; Moron Fuenmayor \& Clavero, 1999). As diferenças são facilmente observadas quando o peso e a idade diferem no período de abate. Cordeiros mais jovens, embora apresentem uma carcaça de melhor qualidade, possuem rendimentos menores do que animais mais velhos, abatidos com maior peso (Lee et al., 1990).

Apesar de os animais terem sido abatidos jovens neste experimento, o rendimento verdadeiro encontrado foi alto, acima de $53 \%$, e o rendimento comercial em torno de 44\%. Vergara et al. (1999), estudando dois pesos de abate, encontraram um rendimento comercial de $46,98 \%$ para cordeiros machos abatidos com um peso médio de $21,73 \mathrm{~kg}$ e $48,74 \%$ para um peso de abate de $27,80 \mathrm{~kg}$. Notter et al. (1991), no abate de animais com peso de $50-55 \mathrm{~kg}$, encontraram uma relação para peso de carcaça quente e peso vivo ao abate em torno de $50 \%$. Esta mesma porcentagem foi observada no trabalho de Stanford et al. (1998) para machos abatidos com um peso vivo de $45 \mathrm{~kg}$.

Suarez et al. (2000), trabalhando com diferentes genótipos e abatendo os animais com 105 dias de idade, obtiveram pesos de abate de 26,6, 35,4 e 31,6 kg com cordeiros Corriedale, Pampinta e $\mathrm{F}_{1}$ Pampinta $\mathrm{x}$ Corriedale, respectivamente. Apesar dos pesos de abate e de carcaça diferirem entre os genótipos, não foi observada diferença significativa em rendimento de carcaça, que variou de 50,9\% a 53,6\%. Segundo Figueiredo et al. (1982), das raças deslanadas criadas no nordeste do Brasil, a Santa Inês é a que apresenta as melhores características de ganho de peso e de carcaça. Embora essa raça tenha sido comparada neste experimento com a raça Hampshire Down, de origem inglesa e altamente especializada para a produção de carne, os cordeiros Santa Inês apresentaram ganho de peso e peso semelhantes aos da raça Hampshire Down, com maior rendimento comercial de carcaça.
Com relação aos componentes não-constituintes da carcaça, o fotoperíodo não afetou nenhuma das variáveis (Tabela 3). Ao contrário do que foi encontrado neste trabalho, Eisemann et al. (1984) observaram um aumento no trato digestório cheio e vazio de cordeiros expostos ao fotoperíodo longo. No caso da raça, foi constatada superioridade da Santa Inês em peso de sangue, coração, pulmão, rins, baço e cauda - os cordeiros Hamphire Down eram caudectomizados -, e da Hampshire Down em peso de pele, patas e de aparelho gastrintestinal cheio. $\mathrm{O}$ maior peso destes componentes prejudicou os cordeiros Hampshire Down com relação ao rendimento de carcaça, mas tanto a pele (lanada) quanto as patas grandes são características típicas desta raça. Os maiores pesos de sangue, coração, pulmão, rins e baço da raça Santa Inês indicam atividades circulatória e respiratória mais intensas nessa raça.

No experimento realizado por Moron Fuenmayor \& Clavero (1999), animais suplementados com concentrado apresentaram maior peso de rins, testículos e fígado do que os não suplementados; cordeiros mantidos somente na pastagem tiveram menor ganho de peso e apresentaram maior peso de intestino cheio. Segundo esses autores, o crescimento do pulmão, cabeça, patas, coração e pele é influenciado pela idade, raça e sexo do animal.

As medidas de $\mathrm{pH}$ encontradas são características das carnes de cordeiros que não foram afetadas pelo estresse em períodos próximos ao do abate. Segundo Vergara \& Gallego (1999), os valores de $\mathrm{pH}$ observados indicam que a espécie ovina é menos sensível ao estresse do abate do que suínos e bovinos. De acordo com os experimentos que avaliaram as características sensoriais da carne, o pH normal é essencial para a adequada transformação do músculo em carne, sendo considerado um dos fatores que interferem na qualidade da carne produzida, principalmente na maciez, suculência e coloração (Hopkins \& Fogarty, 1998; Myhara et al., 2000).

O fotoperíodo e a raça não afetaram significativamente o pH medido logo após o abate, 45 minutos e 24 horas após (Tabela 4). De acordo com Hopkins \& Fogarty (1998), embora as condições pré-abate tenham sido semelhantes para todos os cordeiros e as atividades tenham sido realizadas de forma a minimizar o estresse, foram observadas diferenças significativas entre os genótipos estudados. Segundo esses autores, alguns genótipos podem responder diferentemente ao 
estresse associado com o abate ou apresentarem níveis diferentes de glicogênio no músculo, o que causaria variações no $\mathrm{pH}$. Neste trabalho, os cordeiros Hampshire Down e Santa Inês não diferiram quanto ao $\mathrm{pH}$ e ao decréscimo de $\mathrm{pH}, 45$ minutos e 24 horas após o abate.

Outras características como peso de abate (Vergara et al., 1999), deposição de gordura na carcaça (Sanudo et al., 2000), duração do período de aleitamento (Vergara \& Gallego, 1999) e sexo (Vergara \& Gallego, 1999; Vergara et al., 1999) têm pouca influência no pH do músculo. Com relação ao tipo de alimentação, podem ocorrer variações. No trabalho realizado por Hopkins \& Nicholson (1999), não foi observada diferença no $\mathrm{pH}$ em função do tipo de pasto e suplemento utilizado, entretanto, Hopkins \& Fogarty (1998) observaram $\mathrm{pH}$ mais elevado para cordeiros mantidos somente em pastagens, o que foi atribuído às baixas reservas de glicogênio.

Verificou-se que o fotoperíodo não afetou o comprimento externo e interno da carcaça, a largura e perímetro de garupa nem o comprimento da perna, entretanto cordeiros Santa Inês apresentaram uma largura de garupa e um comprimento de perna maiores do que os cordeiros Hampshire Down (Tabela 5). Quanto aos índices de compacidade da carcaça e da perna e aos graus de gordura e de conformação, somente se constatou diferença entre as raças no grau de conformação (Tabela 5). Os cordeiros Hampshire Down apresentaram melhor valor do que os cordeiros Santa Inês. De acordo com a revisão realizada por Stanford et al. (1998), os graus de conformação e gordura são medidas subjetivas que auxiliam na avaliação da carcaça e estão rela-

Tabela 4. Valores de pH (médias \pm desvio-padrão) no momento do abate e aos 45 minutos e 24 horas após o abate, nas carcaças de cordeiros Santa Inês e Hampshire Down, sob dois fotoperíodos.

\begin{tabular}{|c|c|c|c|c|}
\hline \multirow[t]{2}{*}{ Raça } & \multicolumn{2}{|c|}{ Fotoperíodo } & \multirow[t]{2}{*}{ Média } & \multirow[t]{2}{*}{$\mathrm{CV}(\%)$} \\
\hline & Curto & Longo & & \\
\hline & & $\mathrm{pH}, 0 \mathrm{~min}$ & & \\
\hline Santa Inês & $6,51 \pm 0,23$ & $6,42 \pm 0,18$ & 6,46 & 3,11 \\
\hline Hampshire Down & $6,43 \pm 0,21$ & $6,46 \pm 0,17$ & 6,44 & \\
\hline \multirow[t]{2}{*}{ Média } & 6,47 & 6,44 & & \\
\hline & & $\mathrm{pH}, 45 \mathrm{~min}$ & & \\
\hline Santa Inês & $6,23 \pm 0,21$ & $6,13 \pm 0,20$ & 6,18 & 3,59 \\
\hline Hampshire Down & $6,23 \pm 0,23$ & $6,19 \pm 0,24$ & 6,21 & \\
\hline \multirow[t]{2}{*}{ Média } & 6,23 & 6,16 & & \\
\hline & & $\mathrm{pH}, 24$ horas & & \\
\hline Santa Inês & $5,75 \pm 0,12$ & $5,75 \pm 0,15$ & 5,75 & 3,38 \\
\hline Hampshire Down & $5,72 \pm 0,13$ & $5,70 \pm 0,31$ & 5,71 & \\
\hline Média & 5,74 & 5,73 & & \\
\hline
\end{tabular}

cionadas entre si. Normalmente as carcaças com boa conformação possuem mais gordura do que as malconformadas. Osorio et al. (1996), comparando cinco raças - Merino, Ideal, Corriedale, Romney Marsh e Texel -, constataram que a raça Texel revelou melhores índices de compacidade e grau de conformação, por causa da seleção para esses caracteres, que devem ser considerados nas raças de aptidão para carne.

O fotoperíodo curto propiciou maior peso de pescoço. Os pesos de paleta, costela descoberta e baixos foram maiores nos cordeiros Santa Inês. $\mathrm{Na}$ análise das porcentagens dos cortes, observou-se que os cordeiros

Tabela 5. Médias \pm desvio-padrão de mensurações objetivas e subjetivas na carcaça de cordeiros Santa Inês e Hampshire Down, sob dois fotoperíodos ${ }^{(1)}$.

\begin{tabular}{|c|c|c|c|c|}
\hline \multirow[t]{2}{*}{ Raça } & \multicolumn{2}{|c|}{ Fotoperíodo } & \multicolumn{2}{|c|}{ Média CV (\%) } \\
\hline & Curto & Longo & & \\
\hline & \multicolumn{4}{|c|}{ Comprimento externo da carcaça $(\mathrm{cm})$} \\
\hline Santa Inês & $57,29 \pm 1,38$ & $56,57 \pm 1,51$ & 56,93 & 3,03 \\
\hline Hampshire Down & $55,43 \pm 1,72$ & $57,43 \pm 2,15$ & 56,43 & \\
\hline \multirow[t]{2}{*}{ Média } & 56,36 & 57,00 & & \\
\hline & \multicolumn{4}{|c|}{ Comprimento interno da carcaça $(\mathrm{cm})$} \\
\hline Santa Inês & $51,14 \pm 2,27$ & $51,71 \pm 1,60$ & 51,43 & 3,31 \\
\hline Hampshire Down & $49,43 \pm 1,62$ & $51,00 \pm 1,00$ & 50,21 & \\
\hline \multirow[t]{2}{*}{ Média } & 50,29 & 51,36 & & \\
\hline & \multicolumn{4}{|c|}{ Largura da garupa $(\mathrm{cm})$} \\
\hline Santa Inês & $16,47 \pm 0,80$ & $15,89 \pm 0,99$ & $16,18 \mathrm{~A}$ & 7,61 \\
\hline Hampshire Down & $14,50 \pm 1,75$ & $15,66 \pm 0,100$ & $15,08 \mathrm{~B}$ & \\
\hline \multirow[t]{2}{*}{ Média } & 15,49 & 15,77 & & \\
\hline & \multicolumn{4}{|c|}{ Comprimento da perna $(\mathrm{cm})$} \\
\hline Santa Inês & $34,86 \pm 1,07$ & $35,29 \pm 0,95$ & $35,07 \mathrm{~A}$ & 2,88 \\
\hline Hampshire Down & $30,43 \pm 0,98$ & $31,43 \pm 0,79$ & $30,93 \mathrm{~B}$ & \\
\hline \multirow[t]{2}{*}{ Média } & 32,64 & 33,36 & & \\
\hline & \multicolumn{4}{|c|}{ Perímetro da garupa $(\mathrm{cm})$} \\
\hline Santa Inês & $51,57 \pm 2,37$ & $51,43 \pm 2,76$ & 51,50 & 4,64 \\
\hline Hampshire Down & $52,14 \pm 2,54$ & $52,00 \pm 1,83$ & 52,07 & \\
\hline \multirow[t]{2}{*}{ Média } & 51,86 & 51,71 & & \\
\hline & \multicolumn{4}{|c|}{ Índice de compacidade da carcaça $(\mathrm{cm})$} \\
\hline Santa Inês & $26,75 \pm 1,96$ & $24,89 \pm 0,89$ & 25,82 & 6,12 \\
\hline Hampshire Down & $26,20 \pm 2,18$ & $25,17 \pm 0,75$ & 25,68 & \\
\hline \multirow[t]{2}{*}{ Média } & 26,47 & 25,03 & & \\
\hline & \multicolumn{4}{|c|}{ Índice de compacidade da perna $(\mathrm{cm})$} \\
\hline Santa Inês & $47,30 \pm 2,74$ & $45,05 \pm 3,05$ & 46,17 & 7,97 \\
\hline Hampshire Down & $47,64 \pm 5,50$ & $49,83 \pm 3,20$ & 48,74 & \\
\hline \multirow[t]{2}{*}{ Média } & 47,47 & 47,44 & & \\
\hline & \multicolumn{4}{|c|}{ Grau de gordura ${ }^{(2)}$} \\
\hline Santa Inês & $2,14 \pm 0,20$ & $1,93 \pm 0,35$ & 2,04 & 13,83 \\
\hline Hampshire Down & $2,29 \pm 0,30$ & $2,18 \pm 0,31$ & 2,32 & \\
\hline \multirow[t]{2}{*}{ Média } & 2,21 & 2,05 & & \\
\hline & \multicolumn{4}{|c|}{ Grau de conformação(3) } \\
\hline Santa Inês & $2,43 \pm 0,28$ & $2,32 \pm 0,43$ & $2,38 \mathrm{~B}$ & 14,67 \\
\hline Hampshire Down & $2,89 \pm 0,40$ & $2,61 \pm 0,38$ & $2,75 \mathrm{~A}$ & \\
\hline Média & 2,66 & 2,46 & & \\
\hline
\end{tabular}


Santa Inês apresentaram valores de baixos e costela descoberta maiores do que os Hampshire Down, sendo que estes últimos apresentaram maior porcentagem de perna (Tabela 6).

Neste experimento, verificou-se maior desenvolvimento da região anterior nos cordeiros Santa Inês, com maiores pesos de paleta, costela descoberta e baixos. Entretanto, por meio da seleção, seria interessante que a proporção de perna aumentasse em relação aos outros cortes, já que é a região mais valorizada em ani- mais produtores de carne. Embora os cordeiros Santa Inês tenham apresentado maior largura de garupa, maior comprimento de perna e mesmo peso de perna que os cordeiros Hampshire Down, estes últimos apresentaram melhor conformação de carcaça e maior porcentagem de perna. Segundo Hopkins \& Fogarty (1998), o genótipo tem uma grande influência na proporção dos cortes e o que se espera das raças cuja aptidão é produção de carne, é um maior desenvolvimento do quarto posterior.

Tabela 6. Pesos e porcentagens dos cortes da meia carcaça de cordeiros Santa Inês e Hampshire Down, sob dois fotoperíodos ${ }^{(1)}$.

\begin{tabular}{|c|c|c|c|c|c|}
\hline \multirow[t]{2}{*}{ Variável } & \multirow[t]{2}{*}{ Raça } & \multicolumn{2}{|c|}{ Fotoperíodo } & \multirow[t]{2}{*}{ Média } & \multirow[t]{2}{*}{$\mathrm{CV}(\%)$} \\
\hline & & Curto & Longo & & \\
\hline \multirow[t]{2}{*}{ Paleta (kg) } & Santa Inês & $1,49 \pm 0,12$ & $1,40 \pm 0,49$ & $1,44 \mathrm{~A}$ & 6,48 \\
\hline & Hampshire Down & $1,36 \pm 0,11$ & $1,36 \pm 0,07$ & $1,36 \mathrm{~B}$ & \\
\hline Média & & 1,42 & 1,38 & & \\
\hline \multirow[t]{2}{*}{ Pescoço (kg) } & Santa Inês & $0,549 \pm 0,060$ & $0,460 \pm 0,059$ & 0,505 & 10,60 \\
\hline & Hampshire Down & $0,476 \pm 0,046$ & $0,483 \pm 0,040$ & 0,479 & \\
\hline Média & & $0,512 \mathrm{a}$ & $0,471 \mathrm{~b}$ & & \\
\hline \multirow[t]{2}{*}{ Costela descoberta $(\mathrm{kg})$} & Santa Inês & $0,466 \pm 0,119$ & $0,469 \pm 0,080$ & $0,467 \mathrm{~A}$ & 19,06 \\
\hline & Hampshire Down & $0,392 \pm 0,035$ & $0,367 \pm 0,066$ & $0,380 \mathrm{~B}$ & \\
\hline Média & & 0,429 & 0,418 & & \\
\hline \multirow[t]{2}{*}{ Costela (kg) } & Santa Inês & $0,644 \pm 0,125$ & $0,547 \pm 0,043$ & 0,595 & 13,82 \\
\hline & Hampshire Down & $0,584 \pm 0,077$ & $0,556 \pm 0,051$ & 0,570 & \\
\hline Média & & 0,614 & 0,551 & & \\
\hline \multirow[t]{2}{*}{ Lombo $(\mathrm{kg})$} & Santa Inês & $0,685 \pm 0,043$ & $0,657 \pm 0,066$ & 0,671 & 9,25 \\
\hline & Hampshire Down & $0,649 \pm 0,068$ & $0,650 \pm 0,065$ & 0,650 & \\
\hline Média & & 0,667 & 0,654 & & \\
\hline \multirow[t]{2}{*}{ Baixo (kg) } & Santa Inês & $0,894 \pm 0,089$ & $0,853 \pm 0,074$ & $0,874 \mathrm{~A}$ & 10,83 \\
\hline & Hampshire Down & $0,757 \pm 0,099$ & $0,754 \pm 0,090$ & $0,756 \mathrm{~B}$ & \\
\hline Média & & 0,825 & 0,803 & & \\
\hline \multirow{2}{*}{ Pernas (kg) } & Santa Inês & $2,25 \pm 0,08$ & $2,21 \pm 0,11$ & 2,23 & 7,10 \\
\hline & Hampshire Down & $2,29 \pm 0,23$ & $2,21 \pm 0,17$ & 2,25 & \\
\hline Média & & 2,27 & 2,21 & & \\
\hline \multirow[t]{2}{*}{ Palheta $(\%)$} & Santa Inês & $21,36 \pm 1,70$ & $21,23 \pm 1,07$ & 21,29 & 5,41 \\
\hline & Hampshire Down & $20,89 \pm 0,57$ & $21,26 \pm 0,95$ & 21,08 & \\
\hline Média & & 21,12 & 21,25 & & \\
\hline \multirow[t]{2}{*}{ Pescoço $(\%)$} & Santa Inês & $7,88 \pm 0,84$ & $6,97 \pm 0,75$ & 7,42 & 8,82 \\
\hline & Hampshire Down & $7,32 \pm 0,45$ & $7,56 \pm 0,49$ & 7,44 & \\
\hline Média & & 7,60 & 7,26 & & \\
\hline \multirow[t]{2}{*}{ Costela descoberta (\%) } & Santa Inês & $6,67 \pm 1,63$ & $7,09 \pm 1,12$ & $6,88 \mathrm{~A}$ & 17,88 \\
\hline & Hampshire Down & $6,04 \pm 0,63$ & $5,75 \pm 0,95$ & $5,90 \mathrm{~B}$ & \\
\hline Média & & 6,36 & 6,42 & & \\
\hline \multirow[t]{2}{*}{ Costela (\%) } & Santa Inês & $9,19 \pm 1,39$ & $8,29 \pm 0,49$ & 8,74 & 10,81 \\
\hline & Hampshire Down & $8,95 \pm 0,63$ & $8,74 \pm 0,01$ & 8,85 & \\
\hline Média & & 9,07 & 8,51 & & \\
\hline \multirow{2}{*}{ Lombo (\%) } & Santa Inês & $9,83 \pm 0,40$ & $9,95 \pm 0,78$ & 9,89 & 8,81 \\
\hline & Hampshire Down & $9,98 \pm 0,79$ & $10,23 \pm 1,30$ & 10,10 & \\
\hline Média & & 9,90 & 10,09 & & \\
\hline \multirow[t]{2}{*}{ Baixo (\%) } & Santa Inês & $12,83 \pm 1,14$ & $12,94 \pm 1,13$ & $12,88 \mathrm{~A}$ & 9,57 \\
\hline & Hampshire Down & $11,64 \pm 1,24$ & $11,81 \pm 1,20$ & $11,73 \mathrm{~B}$ & \\
\hline Média & & 12,24 & 12,37 & & \\
\hline \multirow{2}{*}{ Perna (\%) } & Santa Inês & $32,26 \pm 1,39$ & $33,54 \pm 1,37$ & $32,90 \mathrm{~B}$ & 4,57 \\
\hline & Hampshire Down & $35,17 \pm 1,75$ & $34,66 \pm 1,66$ & $34,91 \mathrm{~A}$ & \\
\hline Média & & 33,71 & 34,10 & & \\
\hline
\end{tabular}

(1)Médias \pm desvio-padrão seguidas de letras diferentes, minúsculas nas linhas e maiúsculas nas colunas, diferem entre si a 5\% de probabilidade pelo teste de Tukey; CV: coeficiente de variação. 


\section{Conclusões}

1. O fotoperíodo não influencia as características de carcaça e tampouco os componentes não-constituintes da carcaça dos cordeiros Santa Inês e Hampshire Down.

2. Os cordeiros Santa Inês apresentam maior peso de carcaça quente e maior rendimento comercial do que os cordeiros Hampshire Down, porém, a perda no resfriamento da carcaça é maior no Santa Inês.

3. Os cordeiros Hampshire Down apresentam pesos maiores de pele, patas e aparelho gastrintestinal cheio e os Santa Inês, pesos superiores de sangue, coração, pulmão, rins e baço.

4. A largura de garupa e o comprimento de perna são maiores no Santa Inês, entretanto, os cordeiros Hampshire Down apresentam melhor conformação de carcaça.

5. O peso de paleta e os pesos e as porcentagens de costela descoberta e baixos são maiores nos cordeiros Santa Inês, e os cordeiros Hampshire Down apresentam maior porcentagem de perna.

\section{Referências}

BRINKLOW, B.R.; FORBES, J.M. Effect of extended photoperiod on growth of sheep. In: ROCHE, J.F. (Ed.). Manipulation of growth in farm animals. Netherlands: Kluwer Academic Publishers Group, 1984. p.260-273.

BUTLER, L.G. Fatores que afetam a resistência da mecha com particular referência a Tasmânia. Wool Technology Sheep Breeding, v.42, p.213-220, 1994.

COLOMER-ROCHER, F.; ESPEJO, M.D. Determinación del peso optimo de sacrifício de los corderos procedentes del cruzamento Manchega x Rasa Aragonesa en función del sexo. Revista Itea, p.219-225, 1972.

DIMSOSKI, P.; TOSH, J.J.; CLAY, J.C.; IRVIN, K.M. Influence of management system on litter size, lamb growth, and carcass characteristics in sheep. Journal of Animal Science, v.77, p.10371043, 1999.

EISEMANN, J.H.; BAUMAN, D.E.; HOGUE, D.E.; TRAVIS, H.F. Evaluation of a role for prolactin in growth and the photoperiodinduced growth response in sheep. Journal of Animal Science, v.59, p.86-94, 1984.

FIGUEIREDO, E.A.P.; SIMPLICIO, A.A.; RIERA, G.S.; PANT, K.P. Preliminary studies on the carcass characteristics of native breeds of woolless sheep in hot tropical semiarid northeast Brazil. Pesquisa Agropecuária Brasileira, v.17, p.951-960, 1982.
FORBES, J.M. Effects of lighting pattern on growth, lactation and food intake of sheep, cattle and deer. Livestock Production Science, v.9, p.361-374, 1982.

HOPKINS, D.L.; FOGARTY, N.M. Diverse lamb genotypes: 1. Yield of saleable cuts and meat in the carcass and the prediction of yield. Meat Science, v.49, p.459-475, 1998.

HOPKINS, J.A.; NICHOLSON, A. Meat quality of wether lambs grazed on either saltbush (Atriplex nummularia) plus supplements or lucerne (Medicago sativa). Meat Science, v.51, p.91-95, 1999.

KANN, G. Evidence for a mammogenic role of growth hormone in ewes: effects of growth hormone-releasing factor during artificial induction of lactation. Journal of Animal Science, v.75, p.25412549, 1997.

LEE, G.J.; HARRIS, D.C.; FERGUSSON, B.D.; JELBART, R.A. Growth and carcass fatness of ewe, wether, ram and cryptorchid crossbreed lambs reared at pasture: effects of weaning age. Australian Journal of Experimental Agriculture, v.30, p.743-747, 1990.

McCLURE, K.E.; SOLOMON, M.B.; PARRETT, N.A.; VAN KEUREN, R.W. Growth and tissue accretion of lambs fed concentrate in drylot, grazed on alfafa or ryegrass at weaning, or after backgrounding on ryegrass. Journal of Animal Science, v.73, p.3437-3444, 1995.

McCluRE, K.E.; VAN KEUREN, R.W.; ALThOUSE, P.G. Performance and carcass characteristics of weaned lambs either grazed on orchardgrass, ryegrass, or alfafa or fed all-concentrate diets in drylot. Journal of Animal Science, v.72, p.3230-3237, 1994.

MORON FUENMAYOR, O.E.; CLAVERO, T. The effect of feeding system on carcass characteristics, non-carcass components and retail cut percentages of lambs. Small Ruminant Research, v.34, p.5764, 1999.

MYHARA, R.M.; BYERLEY, D.J.; MAHGOUB, O.; CHESWORTH, J.M. Effects of testicular status and feeding diets containing date palm by-product on the sensory attributes of Omani lamb meat. Small Ruminant Research, v.38, p.57-61, 2000.

NOTTER, D.R.; KELLY, R.F.; MCCLAUGHERTY, F.S. Effects of ewe breed and management system on efficiency of lamb production: 2. Lamb growth, survival and carcass characteristics. Journal of Animal Science, v.69, p.22-33, 1991.

NATIONAL RESEARCH COUNCIL. Nutrient requirements of sheep. $6^{\text {th }}$ ed. Washington, D.C.: National Academy Press, 1985. 99 .

OSORIO, J.C.; OLIVEIRA, N.M.; NUNES, A.P.; POUEY, J.L. Produção de carne em ovinos de cinco genótipos: 3. Perdas e morfologia. Ciencia Rural, v.26, p.477-481, 1996.

OTTO, C.; SÁ, J.L.; WOEHL, A.H.; CASTRO, J.A.; REIFUR, L.; VALENTINI, V.M. Estudo econômico da terminação de cordeiros à 
pasto e em confinamento. Revista do Setor de Ciências Agrárias, v.16, p.223-227, 1997.

SAÑUDO, C.; ALFONSO, M.; SANCHEZ, A.; DELFA, R.; TEIXEIRA, A. Carcass and meat quality in light lambs from different fat classes in the EU carcass classification system. Meat Science, v.56, p.89-94, 2000.

SAS INSTITUTE (Cary, Estados Unidos). SAS/STAT user's guide: language and procedures, version 6. Cary, 1989. 638p.

STANFORD, K.; JONES, S.D.M.; PRICE, M.A. Methods of predicting lamb carcass composition: a review. Small Ruminant Research, v.29, p.241-254, 1998.
SUAREZ, V.H.; BUSETTI, M.R.; GARRIZ, C.A.; GALLINGER, M.M.; BABINEC, F.J. Pre-weaning growth, carcass traits and sensory evaluation of Corriedale, Corriedale X Pampinta and Pampinta lambs. Small Ruminant Research, v.36, p.85-89, 2000. VERGARA, H.; GALLEGO, L. Effect of type of suckling and length of lactation period on carcass and meat quality in intensive lamb production systems. Meat Science, v.53, p.211-215, 1999.

VERGARA, H.; MOLINA, A.; GALLEGO, L. Influence of sex and slaughter weight on carcass and meat quality in light and medium weight lambs produced in intensive systems. Meat Science, v.52, p.221-226, 1999.

$\overline{\text { Recebido em } 18 \text { de setembro de } 2003 \text { e aprovado em } 7 \text { de janeiro de } 2005}$ 